\title{
A Compact Microstrip Patch Antenna Based on Metamaterials for Wi-Fi and WiMAX Applications
}

\author{
Suman Nelaturi ${ }^{*}$ Nookala Venkata Satya Narasimha Sarma
}

\begin{abstract}
A low profile asymmetrical fractal boundary patch antenna based on reactive impedance surface (RIS) and a mushroom unit cell (MUC) is proposed and studied for dual band operation. The sides of the square patch antenna are replaced with asymmetrical half circled fractal curves for circular polarization operation at patch mode band. The fractal patch antenna is loaded with MUC for dual band operation. The antenna radiation characteristics are investigated and illustrated with both simulated and experimental results in detail. The $10-\mathrm{dB}$ return loss bandwidth are 8.48\% (3.21-3.49 GHz) and 2.59\% (2.30-2.36 GHz) at upper and lower resonance frequencies, respectively. The 3-dB axial ratio bandwidth is $4.26 \%(3.21-3.35 \mathrm{GHz})$. A close agreement between simulation data with experimental results is observed.
\end{abstract}

Key Words: Circular Polarization, Fractal Boundary Patch Antenna, Mushroom Unit Cell, Reactive Impedance Surface.

\section{INTRODUCTION}

Miniaturized patch antennas with circular polarization $(\mathrm{CP})$ are widely used in present day wireless communication systems. $\mathrm{CP}$ antennas are able to attenuate multipath effects and allow the information transmission autonomous of the orientation of the receiver with reference to transmitter. In general, $\mathrm{CP}$ microstrip patch antennas can be divided into two categories: single feed type and dual feed type. The dual feed type $\mathrm{CP}$ microstrip patch antennas can provide wider $\mathrm{CP}$ bandwidth but they are large in size and require a complicated feeding network [1-3]. The single feed type CP microstrip patch antennas involves an orthogonal pair of modes with $90^{\circ}$ phase shift, which usually requires a suitable feeding position and a small disturbance on the antenna structure to excite the orthogonal modes, such as slots, slits and truncated corners. Be that as it may, these customary procedures offer no size diminishment [4-6].
Metamaterials are the smart materials engineered to have properties that have not yet been found in nature. Novel antennas like dual band dual polarized antennas are designed by using metamaterials because of their artificial electromagnetic properties. Split-ring resonators (SRRs) and wires are the basic metamaterials. Composite right/left-handed (CRLH) structures are another type of metamaterials, which are used to achieve zero and negative order modes. Microstrip patch antenna loaded with mushroom unit cell (MUC) is able to excite the negative order resonances and provide decreased resonance frequencies, thus enabling the antenna miniaturization [7-12]. These materials have been used for multiband applications. The reactive impedance surface (RIS) is used to provide a zero reflection phase at a particular frequency $[13,14]$. The compactness and circular polarization operation can be achieved by applying fractal curves to the edges of the square patch $[15,16]$.

In this paper, MUC loaded compact single probe-feed

Manuscript received February 5, 2018 ; Revised April 27, 2018 ; Accepted June 2, 2018. (ID No. 20180205-013J)

Department of Electronics and Communications Engineering, The National Institute of Technology, Warangal, India.

"Corresponding Author: Suman Nelaturi (e-mail: nelaturi.suman4@gmail.com)

This is an Open-Access article distributed under the terms of the Creative Commons Attribution Non-Commercial License (http://creativecommons.org/licenses/by-nc/4.0) which permits unrestricted non-commercial use, distribution, and reproduction in any medium, provided the original work is properly cited.

(c) Copyright The Korean Institute of Electromagnetic Engineering and Science. All Rights Reserved. 
asymmetrical fractal patch antenna based on RIS is proposed. The detailed fractal antenna design, CP working principle and radiation characteristics are then presented. The measured results are in good agreement with the simulated results which are obtained from the HFSS simulation.

\section{PROPOSED ANTENNA GEOMETRY AND SIMULATED RESULTS}

The structure of the proposed antenna which is fed by single coaxial probe feed is shown in the Fig. 1. It is a three layer structure where the top and bottom dielectric substrates are "FR4 epoxy" with a dielectric constant of 4.4 (Fig. 2). The RIS is sandwiched between these dielectric materials and is composed of $4 \times 4$ periodic planar array of metallic asymmetrical fractal patches. The optimized dimensions of the suggested antenna are listed in Table 1.

Fractals are analyzed by two important factors: iteration order (IO) and indentation factor. For semi-circle fractal curves, the indentation factor is indentation radius (IR). The proposed square patch length is $\mathrm{L} 2$ and $\mathrm{rx}$ and ry are IRs along the $\mathrm{x}$ - and $\mathrm{y}$-axes. The $\mathrm{CP}$ operation is accomplished by deploying the fractal semi-circled curves. The four sides of the square patch antenna are etched with fractal curves of different IRs. Two orthogonal modes with $90^{\circ}$ phase shift are introduced for CP radiation with the use of asymmetrical fractal curves along the sides of the square patch antenna.

Single fractal MUC is inserted into the fractal patch antenna to get the double band. To separate the RIS from VIA and feed, two separate holes are etched from the RIS so that VIA and feed do not touch the RIS. Desirable CP bandwidth can be obtained by adjusting the slot position on the patch and mush-

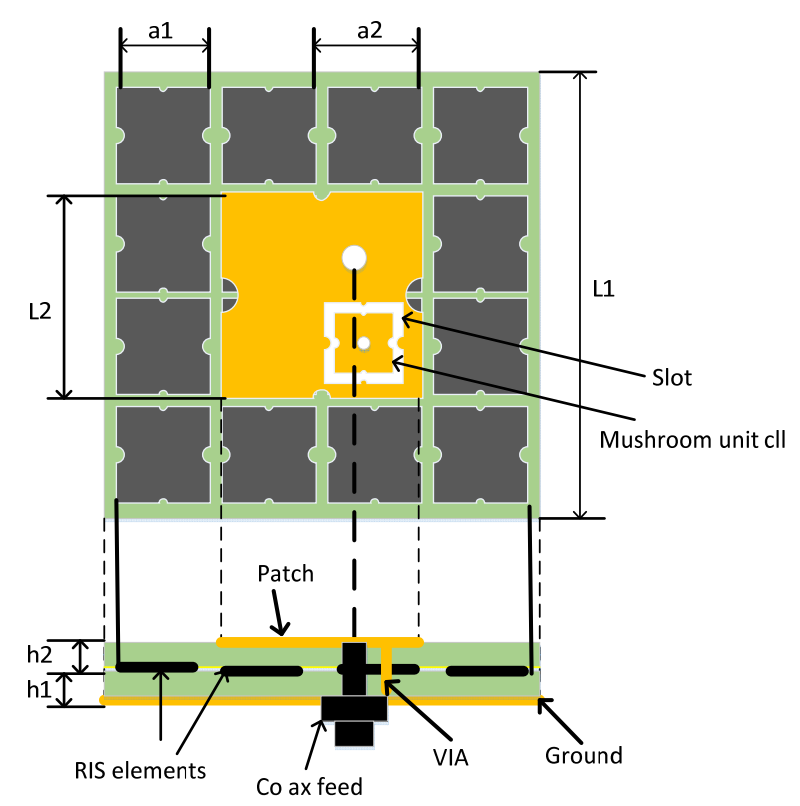

Fig. 1. Structure of the proposed fractal $\mathrm{CP}$ patch antenna.

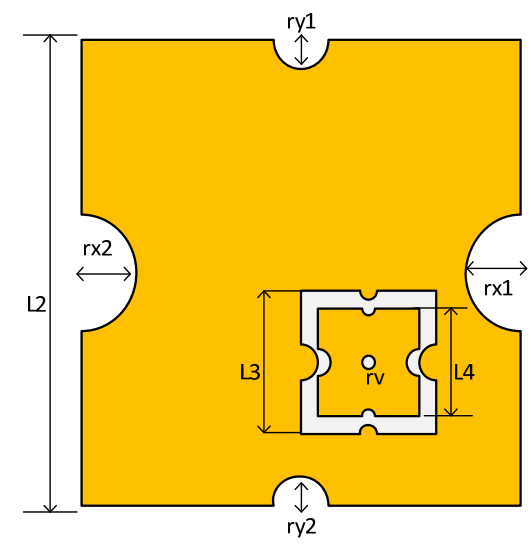

(a)

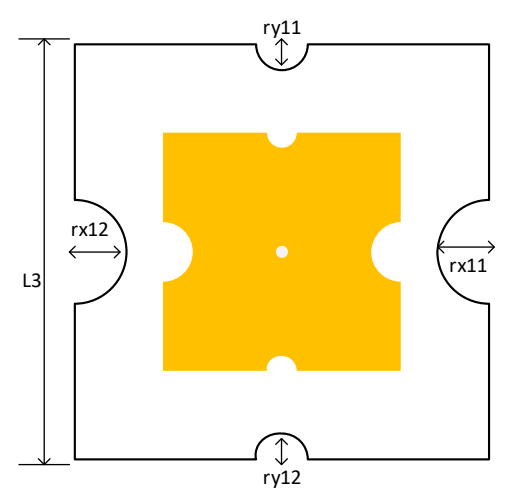

(b)

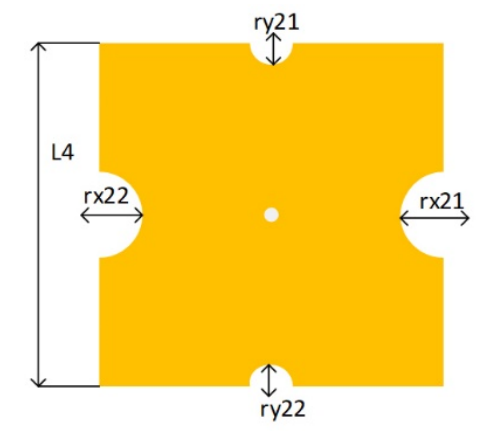

(c)

Fig. 2. Structure of the CP patch antenna. (a) Patch antenna with slot and mushroom unit cell, (b) slot with mushroom unit cell, and (c) mushroom unit cell.

room position. The patch and MUC are capacitively coupled by a small gap. Because of mushroom unit structure a lower resonance frequency band is occurred.

Half circled or semi-circled fractal curves are characterized by two parameters, IO and IR. Equal IR $(r \times 1=r \times 2=r y 1=r y 2)$ along four sides of the square patch antenna results in linear polarization at upper frequency band. Circular polarization radiation can be obtained by loading different IRs along each side of the patch $(r x 1 \neq \mathrm{rx} 2 \neq \mathrm{ry} 1 \neq \mathrm{ry} 2)$ or $(\mathrm{rx} 1=\mathrm{rx} 2=\mathrm{rx} \neq \mathrm{ry} 1=$ ry $2=$ ry). High bandwidth can be obtained when IRs along same axis are equal and are not equal along the perpendicular 
Table 1. Optimized parameter values

\begin{tabular}{cc}
\hline Parameter & Value $(\mathrm{mm})$ \\
\hline L1 & 35 \\
L2 & 18 \\
h1 & 2.6 \\
h2 & 0.4 \\
a1 & 7 \\
a2 & 9 \\
L3 & 7 \\
L4 & 6 \\
rv & 0.5 \\
rx1 & 1 \\
rx2 & 1 \\
ry1 & 0.5 \\
ry2 & 0.5 \\
\hline
\end{tabular}

axis $(\mathrm{rx} 1=\mathrm{rx} 2=\mathrm{rx} \neq \mathrm{ry} 1=\mathrm{ry} 2=\mathrm{ry})$. The reflection phase characteristics of the RIS MUCs are shown in Fig. 3.

Operation of the proposed design can be understood by considering an evolution of patch antenna design shown in Fig. 4. Initially a square patch with $18 \mathrm{~mm} \times 18 \mathrm{~mm}$ is chosen as reference which is implemented on different types of RIS for single-band operation. The RIS of Ant1 is composed of $5 \times 5$ planar array of square elements with each element size is $5 \mathrm{~mm}$. Ant2 has $5 \times 5$ planar array of each element size is $6 \mathrm{~mm}$. Ant 3 has planar array of each element size is $7 \mathrm{~mm}$. Ant4 has planar array of each element size is $8 \mathrm{~mm}$. From the above four antennas Ant3 is selected for dual-band operation because of its high impedance bandwidth. Ant5 is designed with square RIS (all elements are square) and fractal MUC loaded square patch for dual-band dual-polarization operation. Ant6 designed by introducing asymmetrical fractal curves to patch in Ant5. Ant7 is obtained from Ant5 by introducing fractal curves to each element of RIS. Ant8 is designed by introducing fractal curves to both patch and each element of RIS. Finally Ant8 is the proposed antenna with dual-band dual-polarization.

The simulated return loss characteristics of single band an-
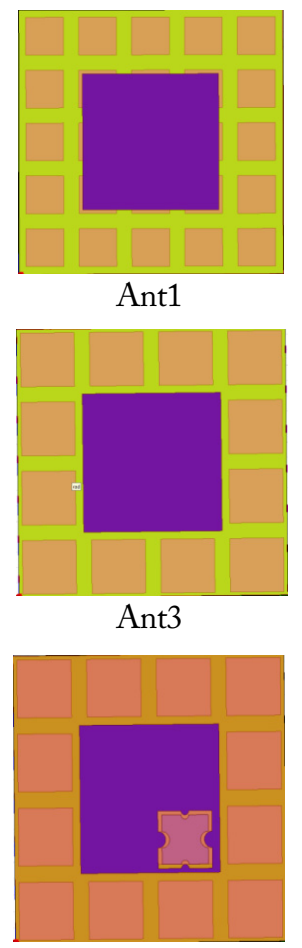

Ant5

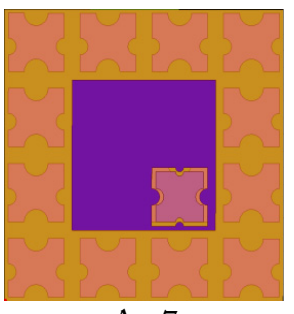

Ant7

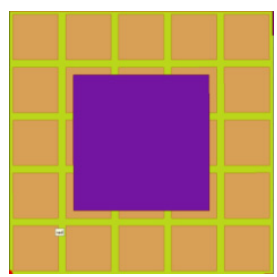

Ant2

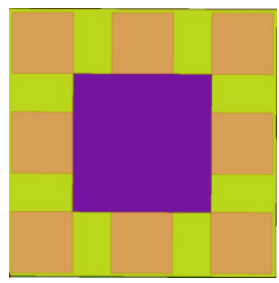

Ant4

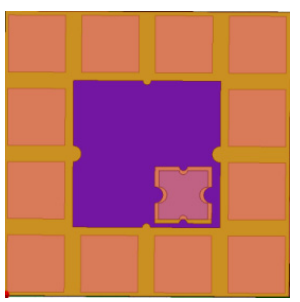

Ant6

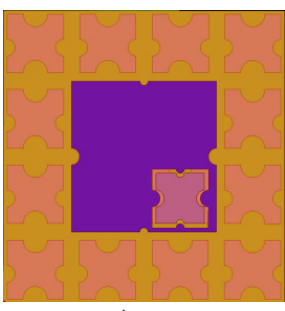

Ant8

Fig. 4. Proposed antenna structures.

tennas from Ant1 to Ant 4 are shown in Fig. 5 and the $10-\mathrm{dB}$ return loss bandwidth of each antenna is listed in Table 2 .

The simulated return loss characteristics of all dual-band dual-polarized antennas from Ant5 to Ant8 are shown in Fig. 6 and the impedance bandwidth at two resonating bands of each

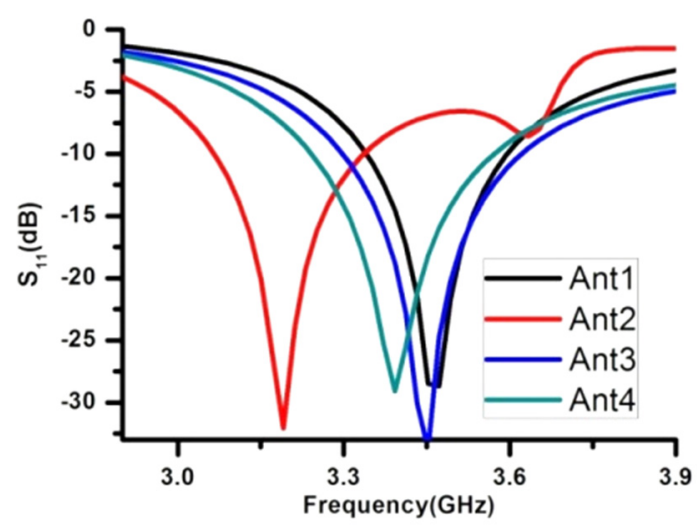

Fig. 5. Simulated return loss characteristics of single band antennas Ant1-Ant4.

Fig. 3. Reflection phase characteristics of the RIS unit cells. 
Table 2. Simulated impedance bandwidth of single band antennas

\begin{tabular}{cccc}
\hline & $\begin{array}{c}\text { No. of RIS } \\
\text { elements }\end{array}$ & $\begin{array}{c}\text { RIS element } \\
\text { size }(\mathrm{mm})\end{array}$ & $\begin{array}{c}\text { 10-dB return loss }(\%) \\
\text { bandwidth }(\mathrm{GHz})\end{array}$ \\
\hline Ant1 & 25 & $\mathrm{a} 1=5, \mathrm{a} 2=7$ & 6.91 \\
Ant2 & 25 & $\mathrm{a} 1=6, \mathrm{a} 2=7$ & $(3.35-3.59)$ \\
& & & 8.12 \\
Ant3 & 16 & $\mathrm{a} 1=7, \mathrm{a} 2=9$ & $(3.07-3.33)$ \\
& & & 8.82 \\
Ant4 & 9 & $\mathrm{a} 1=8, \mathrm{a} 2=13$ & 8.80 \\
& & & $(3.25-3.55)$ \\
\hline
\end{tabular}

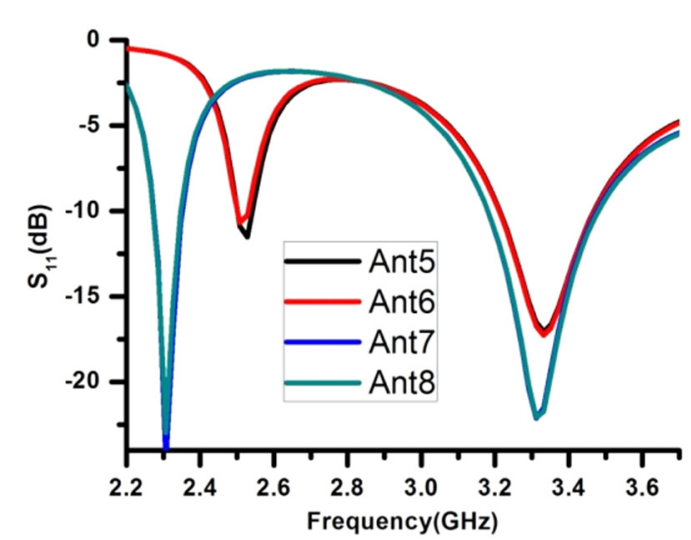

Fig. 6. Simulated return loss characteristics of dual-band antennas Ant5-Ant8.

antenna is listed in Table 3.

\section{EXPERIMENTAL RESULTS}

The proposed antenna (Ant8) is printed on FR4 epoxy material and is shown in Fig. 7. The experimental results of the fabricated $\mathrm{CP}$ patch antenna are compared with the simulated results. The return loss characteristics are shown in Fig. 8. The upper resonance frequency band which is occurred due to RIS

Table 3. Simulated impedance bandwidth of dual-band antennas

\begin{tabular}{ccccc}
\hline & \multirow{2}{*}{ RIS } & Patch & \multicolumn{2}{c}{$\begin{array}{c}\text { 10-dB return loss }(\%) \\
\text { bandwidth }(\mathrm{GHz})\end{array}$} \\
\cline { 4 - 5 } & & & Lower freq. & Upper freq. \\
\hline Ant5 & Square & Square & 0.79 & 6.58 \\
& & & $(2.50-2.52)$ & $(3.23-3.45)$ \\
Ant6 & Square & Fractal & 0.79 & 7.20 \\
& & & $(2.50-2.52)$ & $(3.21-3.45)$ \\
Ant7 & Fractal & Square & 2.59 & 7.78 \\
& & & $(2.28-2.34)$ & $(3.21-3.47)$ \\
Ant8 & Fractal & Fractal & 2.59 & 8.40 \\
(pro- & & & $(2.28-2.34)$ & $(3.19-3.47)$ \\
posed) & & & & \\
\hline
\end{tabular}

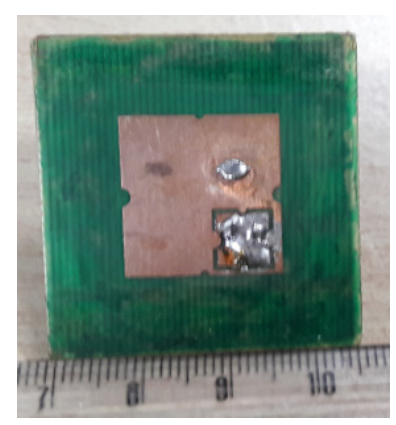

(a)

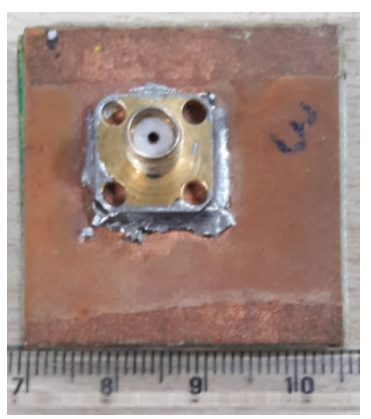

(b)
Fig. 7. Photograph of the fabricated patch antenna: (a) front view and (b) back view.

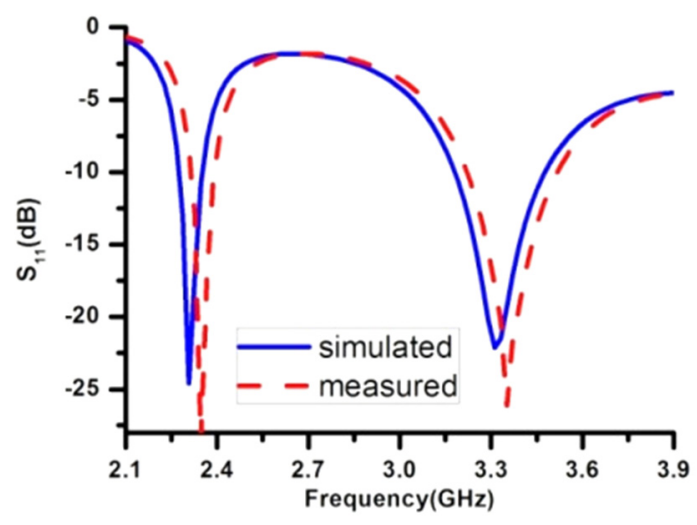

Fig. 8. Return loss characteristics of the fabricated antenna.

and fractal patch results in wide impedance bandwidth that covers $10-\mathrm{dB}$ return loss bandwidth of $8.48 \%$ (3.21-3.49 $\mathrm{GHz}$ ). The lower resonance frequency band which is achieved due to MUC results in 10- $\mathrm{dB}$ return loss bandwidth of $2.59 \%$ (2.302.36 GHz). The axial ratio characteristics are shown in Fig. 9. The measured 3-dB axial ratio bandwidth at upper operating frequency band is $4.26 \%(3.21-3.35 \mathrm{GHz})$.

The measured and simulated radiation patterns of the proposed antenna at lower and upper resonating band are shown in Figs. 10 and 11, respectively. The measured and simulated gain

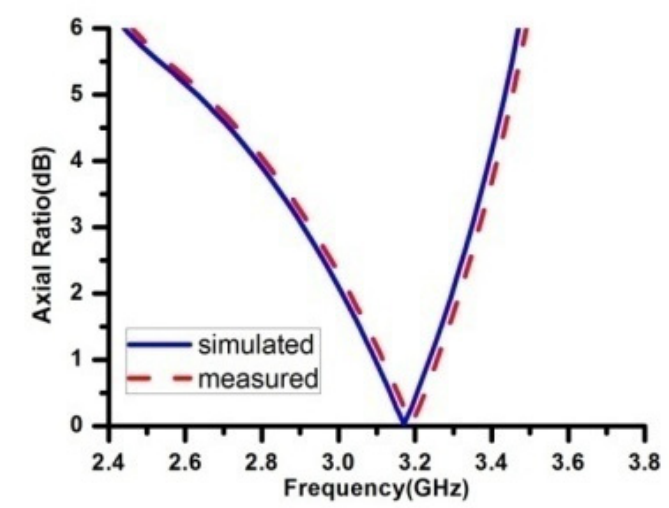

Fig. 9. Axial ratio characteristics of the fabricated patch antenna. 
Table 4. Comparison with existing literature

\begin{tabular}{lccc}
\hline & $\begin{array}{c}\text { Patch size } \\
(\mathrm{mm})\end{array}$ & \multicolumn{2}{c}{$\begin{array}{c}\text { 10-dB return loss bandwidth at corre- } \\
\text { sponding centre frequency }\end{array}$} \\
\cline { 3 - 4 } & & ZOR & Patch mode \\
\hline Proposed & $18 \times 18$ & $2.59 \%$ at $2.3 \mathrm{GHz}$ & $8.4 \%$ at $3 \mathrm{GHz}$ \\
{$[8]$} & $20.4 \times 21.4$ & $\begin{array}{c}\text { Around } 1 \% \text { at } 2.2 \\
\text { GHz }\end{array}$ & $4.6 \%$ at $3 \mathrm{GHz}$ \\
& & $\mathrm{GHz}$ & \\
{$[14]$} & $19.9 \times 19.9$ & $1.38 \%$ at $2.4 \mathrm{GHz}$ & $4.9 \%$ at $3 \mathrm{GHz}$ \\
\hline
\end{tabular}

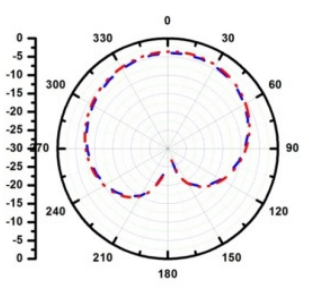

(a)

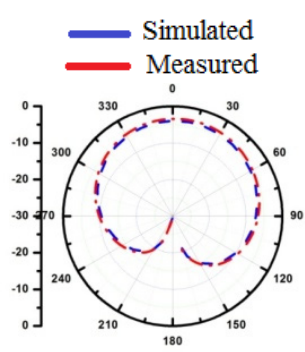

(b)
Fig. 10. Radiation patterns at $2.32 \mathrm{GHz}$. (a) E-plane pattern and (b) H-plane pattern.

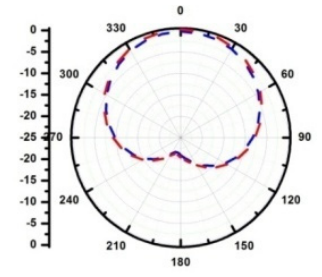

(a)

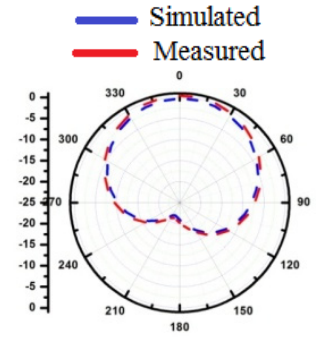

(b)
Fig. 11. Radiation patterns at $3.35 \mathrm{GHz}$. (a) E-plane pattern and (b) H-plane pattern.

of the antenna is given in Fig. 12.

Table 4 gives the comparison of the results of the proposed antenna with antennas which already exist in the literature. The proposed antenna is more compact and produces more bandwidth compared to remaining antennas listed in Table 4.

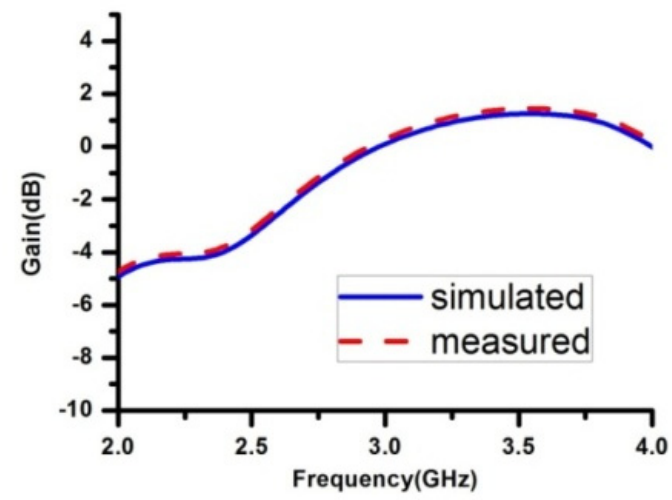

Fig. 12. Gain characteristics of the proposed antenna.

\section{CONCLUSION}

A novel miniaturized single probe feed asymmetrical fractal patch antenna loaded MUC has been studied and presented based on RIS and MUC for dual-band operation. The measured $10-\mathrm{dB}$ return loss bandwidth of antenna prototype are 8.48 $\%$ and $2.59 \%$ at upper and lower resonance frequencies, respectively. The $3-\mathrm{dB}$ axial ratio bandwidth of the antenna prototype is around $4.26 \%$ at upper band. The suggested antenna covers WLAN $(2.4 \mathrm{GHz})$ and WiMAX $(3.4 \mathrm{GHz})$ operating bands.

\section{REFERENCES}

[1] X. M. Qing and Y. W. M. Chia, "Circularly polarised circular ring slot antenna fed by stripline hybrid coupler," Electronics Letters, vol. 35, no. 25, pp. 2154-2155, 1999.

[2] J. S. Row, C. Y. D. Sim, and K. W. Lin, "Broadband printed ring-slot array with circular polarization," Electronics Letters, vol. 41, no. 3, pp. 110-112, 2005.

[3] L. Bian, Y. X. Guo, L. C. Ong, and X. Q. Shi, "Wideband circularly-polarized patch antenna," IEEE Transactions on Antennas and Propagation, vol. 54, no. 9, pp. 2682-2686, 2006.

[4] F. S. Chang, K. L. Wong, and T. W. Chiou, "Low-cost broadband circularly polarized patch antenna," IEEE Transactions on Antennas and Propagation, vol. 51, no. 10, pp. 3006-3009, 2003.

[5] R. Li, G. DeJean, J. Laskar, and M. M. Tentzeris, "Investigation of circularly polarized loop antennas with a parasitic element for bandwidth enhancement," IEEE Transactions on Antennas and Propagation, vol. 53, no. 12, pp. 3930-3939, 2005.

[6] X. Qing and Z. N. Chen, "Compact asymmetric-slit microstrip antennas for circular polarization," IEEE Transactions on Antennas and Propagation, vol. 59, no. 1, pp. 285-288, 2011.

[7] D. Sievenpiper, L. Zhang, R. F. Broas, N. G. Alexopolous, and E. Yablonovitch, "High-impedance electromagnetic surfaces with a forbidden frequency band," IEEE Transactions on Microwave Theory and Techniques, vol. 47, no. 11, pp. 2059-2074, 1999.

[8] Y. Dong, H. Toyao, and T. Itoh, "Compact circularly-polarized patch antenna loaded with metamaterial structures," IEEE Transactions on Antennas and Propagation, vol. 59, no. 11, pp. 4329-4333, 2011.

[9] K. Saurav, D. Sarkar, and K. V. Srivastava, "Dual-polarized dual-band patch antenna loaded with modified mushroom unit cell," IEEE Antennas and Wireless Propagation Letters, vol. 13, pp. 1357-1360, 2014.

[10] Q. Hou, H. Tang, Y. Liu, and X. Zhao, "Dual-frequency and broadband circular patch antennas with a monopole- 
type pattern based on epsilon-negative transmission line," IEEE Antennas and Wireless Propagation Letters, vol. 11, pp. 442-445, 2012.

[11] M. S. Majedi and A. R. Attari, "Dual-band resonance antennas using epsilon negative transmission line," IET Microwaves, Antennas EF Propagation, vol. 7, no. 4, pp. 259-267, 2013.

[12] F. J. Herraiz-Martinez, V. Gonzalez-Posadas, L. E. Garcia-Munoz, and D. Segovia-Vargas, "Multifrequency and dual-mode patch antennas partially filled with left-handed structures," IEEE Transactions on Antennas and Propagation, vol. 56, no. 8, pp. 2527-2539, 2008.

[13] K. Agarwal, Nasimuddin, and A. Alphones, "RIS-based compact circularly polarized microstrip antennas," IEEE

Suman Nelaturi

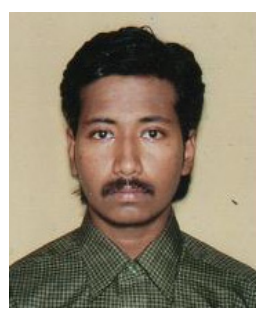

received his B.Tech. degree in 2006 in electronics and communication engineering from Vignan Engineering College affiliated to Jawaharlal Nehru Technological University, Hyderabad, India. He received M.Tech. degree in 2010 in electronics and communication engineering from the Jawaharlal Nehru Technological University, Kakinada, India. Currently, he is working for doctorate in the field of dualband microstrip patch antennas based on metamaterials at the National Institute of Technology Warangal, India. He has publications in six international conferences.
Transactions on Antennas and Propagation, vol. 61, no. 2, pp. 547-554, 2013.

[14] Y. Dong, H. Toyao, and T. Itoh, "Design and characterization of miniaturized patch antennas loaded with complementary split-ring resonators," IEEE Transactions on Antennas and Propagation, vol. 60, no. 2, pp. 772-785, 2012.

[15] V. V. Reddy and N. V. S. N. Sarma, "Compact circularly polarized asymmetrical fractal boundary microstrip antenna for wireless applications," IEEE Antennas and Wireless Propagation Letters, vol. 13, pp. 118-121, 2014.

[16] V. V. Reddy and N. V. S. N. Sarma, "Triband circularly polarized Koch fractal boundary microstrip antenna," IEEE Antennas and Wireless Propagation Letters, vol. 13, pp. 10571060, 2014.

Nookala Venkata Satya Narasimha Sarma

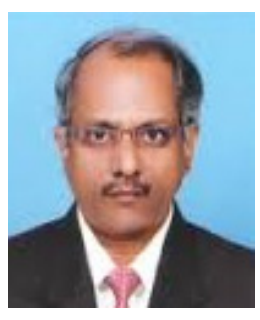

obtained his Bachelor's degree with specialization in electronics and communications engineering from the College of Engineering, Kakinada, Jawaharlal Nehru Technological University in 1984. His Master's and Doctoral degrees are from Indian Institute of Technology, Kharagpur, India in 1985 and 1992, respectively. He worked at Tata Institute of Fundamental Research, Mumbai for a brief period during February 1986 to July 1987. He has been with the Department of Electronics and Communications Engineering at the National Institute of Technology, Warangal, India at various positions since 1990. About 70 papers are at his credit in International and National journals and conferences. His area of interest includes numerical electromagnetics, adaptive antenna arrays, and energy-efficient routing protocols in wireless sensor networks. 